\title{
A INSERÇÃO DOS RECURSOS DIGITAIS E DA INTERNET NAS PRÁTICAS SOCIAIS E EDUCACIONAIS: IMPACTOS NO ENSINO DA LITERATURA DO SÉCULO XXI.
}

\author{
Denise Bértoli Braga \\ denisebb@iel.unicamp.br \\ Ana Flora Schlindwein
}

\section{Analisando a literatura do século XXI a partir de uma perspectiva interdisciplinar}

Ao romper as barreiras temporais e as espaciais, a internet vai também aos poucos demandando uma quebra das fronteiras entre áreas acadêmicas e promovendo interlocuções interdisciplinares, na busca de compreender uma nova realidade social que, além de complexa, encontra-se em constante mudança. O presente estudo partiu de uma iniciativa da área de Literatura, que abriu espaço para olhares interdisciplinares sobre a questão de ensino ${ }^{1}$ de leitura. A pesquisa em foco traz conceitos bastante discutidos na área de Linguística Aplicada na busca de construir uma reflexão teórica e aplicada sobre as mudanças que estão ocorrendo em relação à produção e leitura de textos literários, dada a influência cada vez mais presente do uso da tecnologia digital em nossa sociedade. Reflexões interdisciplinares podem não trazer soluções aprofundadas para os problemas específicos das

I Colóquio Nacional: Literatura e Ensino em Debate (2012), no qual o Prof. Dr. Marcos Lopes - colega de Instituto que atua na área de Literatura - participou como organizador. 
áreas, mas o deslocamento do olhar teórico certamente é útil para levantar novas questões, principalmente em relação ao ensino. A práxis pedagógica é necessariamente interdisciplinar.

A literatura, como todas as demais formas de produção artística, é marcada pela busca de novas formas expressivas, e tal busca é afetada e afeta os referenciais linguísticos eculturais pré-existentes em momentos históricos específicos. Embora a remidiação entre produções artísticas (como romances reproduzidos a partir de uma linguagem fílmica) e a hibridização de formas expressivas existam desde que o ser humano passou a explorar suportes externos à sua memória para registrar textos, esses processos ganharam uma nova dimensão na época atual. Isso pode em parte ser explicado pelos avanços técnicos que hoje permitem integrar em um único suporte um conjunto de linguagens que já circulavam na sociedade no contexto de outras mídias (MANOVICH, 200o). A ampliação desses suportes e a mobilidade que eles adquiriram recentemente - ultrabooks, IPads, Kindles, Smartphones, entre outros - tornaram esses recursos de comunicação e acesso a textos cada vez mais presentes nas atividades cotidianas.

Duas características centrais tipificam grande parte dos textos digitais que circulam na internet: são hipertextuais e multimodais. A noção de hipertexto foi inicialmente teorizada a partir do estudo de textos literários ${ }^{2}$, já que a liberdade que essa organização textual oferecia para caminhos de leitura foi entendida como bastante promissora para a fruição do texto poético. Em relação à multimodalidade, as ferramentas de autoria digitais disponibilizadas online, com interfaces cada vez mais amigáveis, instigaram as pessoas leigas a se tornarem produtores de materiais multimídia e hipermídia, uma atividade que até recentemente demandava a participação de equipes altamente especializadas. Essa maior utilização de programas computacionais por leigos explica as novas formas de produção textual com as mash ups apresentadas, por exemplo, por internautas, e também abre novos caminhos no campo artístico - e suas experimentações - de um modo geral. A título de exemplo, essas novas possibilidades de expressão têm sido incorporadas em trabalhos como os desenvolvidos pela artista plástica Karen Ingham, os quais contestam as fronteiras rígidas até então colocadas entre ciência e arte. Em entrevista ${ }^{3}$ à Satnet ${ }^{4}$, Ingham relata em

${ }^{2}$ Ver Landow, G.P. Hypertext 2.o: The Convergence of Contemporary Critical Theory and Technology. Baltimore e London: The Johns Hopkins University Press, 1997.

3 Disponível em: http://www.youtube.com/watch?v=N4PihjhzStM Acesso em o7ago2014.

${ }^{4}$ Satnet é um grupo de pesquisa vinculado à Swansea Metropolitan University (País de Gales), cujo objetivo é "focus onbuilding new networks across the usually distinct disciplines of the visual arts, the sciences, and technology sectors". 
“The Pollinator Frocks Project”5 (2011) sua preocupação com a diminuição considerável de insetos responsáveis pela polinização de plantas e com o modo como a colaboração entre entomologistas, botânicos, especialistas em estamparia, entre outros profissionais, culminou na produção de coleção de tecidos que eram 'wearable gardens' (algo como "jardins usáveis"). Nessa experiência a autora debate o imbricamento entre áreas consideradas distintas e distantes tais como a biologia, as artes e a produção têxtil, posicionamento que também pode ser visto em seu artigo "Descartes' Eye: Theorising the Art and Science of Observation"6.

Considerando esse movimento mais amplo, o presente estudo reflete sobrea forma como as mudanças nos modos de expressão contemporâneos estão também presentes em algumas iniciativas que buscam inovar o texto literário. Os exemplos selecionados neste artigo ilustram a hibridização de gêneros e linguagens cada vez mais explorados pela literatura e também formas novas e colaborativas de produção e interpretação de textos. Essas reflexões visam abrir caminhos para uma questão mais ampla que precisa ser considerada no campo da educação formal: Quais as mudanças que essas novas formas de expressão suscitam para a formação de leitores de textos literários?

Na sequência, apresentamos os conceitos teóricos que são centrais para a análise a ser discutida no presente estudo.

\section{Linguagens híbridas e remidiação: a produção e a leitura em mídias digitais.}

Ao refletir sobre a relação entre texto e imagem em produções atuais, Jewitt (2005) mostra como ela tem sido reconfigurada nos espaços multimidiáticos. Mais instigante ainda é refletir sobre o modo como essa relação tem se configurado não só em áreas como o jornalismo e o marketing, mas na literatura, principalmente quando nesse cenário são consideradas as novas tecnologias de informação e comunicação. Frente a esse panorama, Snyder (2010, p.272) alerta que "não há uma teoria em particular que, sozinha, dê conta da riqueza, da complexidade, da

5 Disponível em: http://kareningham.org.uk/portfolio/science-art-technology/ pollinator-frocks Disponível em o7ago2014.

${ }^{6}$ Originalmente apresentado em "Beyond Boundaries: Theory' session of the New Constellations: Art, Science and Society, International Conference”. In: RYE, D. C. and SCHEDING, S. J. eds. Proceedings of New Constellations: Art, Science and Society. Museum of Contemporary Art, Sydney, 17-19 March 2006. Sydney: Museum of Contemporary Art. pp. 19-23. 
variedade e da novidade inerentes às práticas de letramento associadas ao uso das novas mídias". De fato, há diferentes perspectivas teóricas que nos ajudam a entender as mudanças nas formas de construção da narrativa literária, dada a presença cada vez mais constante da mediação da tecnologia digital nas práticas cotidianas. Duas noções que podem ser úteis para abordarmos esse processo são a noção de hibridização proposta por Santaella e a de remidiação, na linha delineada por Bolter e Grusin, que comentaremos de forma sintética a seguir.

O conceito de hibridação ou hibridização não é de uso exclusivo de estudos que têm como foco a linguagem e seu universo, sendo adotado por diferentes áreas e com variações de sentido. Originalmente pensado a partir de estudos sobre culturas, o conceito de hibridação elaborado por Canclini (2008) tem sido adotado em inúmeras pesquisas que tratam de questões principalmente no campo da sociolinguística e de estudos de letramento. Para o autor, a hibridação cultural ocorre quando "processos socioculturais nos quais estruturas ou práticas discretas ${ }^{7}$, que existiam de forma separada, se combinam para gerar novas estruturas, objetos e práticas" (2008, p.XIX). O híbrido apresenta elementos das estruturas ou práticas discretas; essas características, porém, não se dão através de um processo de acumulação, mas sim de interpenetração. Essa concepção nos auxilia a entender a complexidade em produções de textos hipermodais cujo funcionamento não pode ser compreendido como a simples soma de seus elementos constitutivos.

O conceito de hibridação cultural também se revela muito prolífero quando buscamos compreender certas manifestações e criações artísticas. Ao refletir sobre as artes - tais como o teatro e apresentações performáticas - Santaella (2003) considera que muitas delas são híbridas, uma vez que são constituídas por "linguagens e meios que se misturam, compondo um todo mesclado e interconectado de sistemas de signos que se juntam para formar uma sintaxe integrada" (Idem, p.135). O desenvolvimento das tecnologias comunicacionais e o surgimento da cibercultura potencializaram, portanto, algo que já ocorria em algumas obras de arte, o que a autora denominou hibridização de elementos textuais, sonoros e visuais. As expressões culturais e formas de se comunicar que ocorrem nesses novos meios "devem pressupor (...) também as misturas entre linguagens que se realizam nas mídias híbridas de que o cinema, a televisão e, muito mais, a hipermídia, são exemplares" (Santaella, 2007, p.78).

7 Deve-se destacar o alerta feito por Canclini (2008, p.XIX) de que as "estruturas chamadas discretas foram resultado de hibridações, razão pela qual não podem ser consideradas fontes puras". 
Jameson (1996) também acredita quegraças às mudanças tecnológicas e midiáticas:

as formas tradicionais dão lugar aos experimentos de mídia mista, ao passo que a fotografia, o cinema e a televisão, todos começam a convergir na obra de arte visual (e também nas outras artes) e a colonizá-la, gerando híbridos high-tech de todos os tipos, das instalações às artes computadorizadas. (idem, p.181)

Em relação ao conceito desenvolvido por Bolter e Grusin, ao analisarem as novas práticas de letramento associadas ao uso das novas tecnologias, ambos afirmam que não há uma ruptura radical com o passado, pois estamos frente à ocorrência de práticas híbridas nas quais o novo e o antigo interagem de forma complexa e instigante:

Novas mídias estão fazendo exatamente o que as suas predecessoras fizeram: se apresentando como versões melhoradas e modernizadas de outras mídias. As mídias digitais podem ser mais bem entendidas através das formas por meio das quais elas honram, rivalizam e revisam a pintura de perspectiva linear, a fotografia, os filmes, a televisão e a imprensa. ${ }^{8}$ (BOLTER e GRUSIN, 1999, p.14)

Os autores citam alguns exemplos úteis para entendermos o conceito: a fotografia remidiou a pintura; o filme fez o mesmo com o teatro e a fotografia; a televisão remidiou o filme, o vaudeville ${ }^{9}$ e o rádio; e o mesmo ocorre com as novas mídias, pois "[t]odas as mídias atuais funcionam como remidiadoras e essa remidiação nos oferece meios de interpretação dos trabalhos de mídias anteriores também”"10 (BOLTER e GRUSIN, 1999, p. 55).

No entanto, os autores alertam para o fato de que a remidiação não é um processo unidirecional no qual apenas uma nova mídia remidia a antiga. Um exemplo de como esse processo se dá em mão dupla é a reformulação do layout de alguns jornais impressos que adotaram a linguagem e o design que são típicos do formato de jornais online. Assim, a "reciclagem", a recombinação de formas e linguagens típicas de certas mídias pode estar presente em diferentes camadas e tanto em mídias novas quanto em mais antigas.

8 "New media are doing exactly what their predecessors have done: presenting themselves as refashioned and improved versions of other media. Digital visual media can best be understood through the ways in which they honor, rival, and revise linearperspective painting, photography, film, television, and print".

9 Vaudeville: espetáculo composto de vários números como dança, mímica, acrobacias, esquetes cômicos, que não apresentam relação entre si. Definição disponível no Dicionário Aulete Digital: http://www.aulete.com.br/Vaudeville Acesso em o7ago2014.

10 "All current media function as remediators and that remediation offer us a means of interpreting the works of earlier media as well". 
Embora para o presente estudo a escolha recaia apenas em exemplos que ilustram a hibridização no nível das formas expressivas e releituras de textos impressos para mídias digitais, em termos teóricos talvez o fator mais complexo e que ainda precisa ser estudado seja o processo transmídia. Também denominado transmídia storytelling, ele é um processo no qual "elementos que constituem uma ficção são sistematicamente dispersos através de múltiplos canais com o intuito de criar uma experiência de entretenimento coordenada e unificada" (JENKINS, 2007, online) e não deve ser confundido com a adaptação (que consiste, por exemplo, em pegar uma história que foi publicada no formato livro e recontá-la no formato fílmico) ou com a extensão (na qual há um acréscimo de informação quando a história passa de um meio para o outro).

Entendendo esse conjunto de mudanças que tem tornado a produção e leitura de textos diferenciada no século XXI, na discussão que segue nos limitamos a analisar exemplos mais simples. Inicialmente, buscamos ilustrar o processo de hibridização de gêneros e linguagens em dois romances impressos. Na sequência comentamos o projeto da filial britânica de uma editora internacional que, visando à promoção de seus autores e de obras impressas de seu catálogo - tantos as tradicionais quanto as que estavam para ser lançadas -, concebeu uma proposta inovadora: usar diferentes tipos de mídias e plataformas para contar histórias.

\section{Mudanças no processo de produção textual no âmbito da literatura.}

\subsection{A migração de gêneros e linguagens na construção de romances.}

Dois romances foram selecionados para ilustrar a influência de gêneros digitais e hibridização de gêneros e linguagem em publicações impressas: The boy next door, da autora Meg Cabot, e A visita cruel do tempo, de Jennifer Egan. O primeiro é uma obra popular que consta na lista dos mais vendidos, e o segundo foi agraciado com o prêmio Pulitzer. O romance The boy next door é inovador na medida em que constrói toda a narrativa a partir de textos de e-mails trocados entre os personagens. Os dados do emissor e destinatário, assim como o tópico das mensagens, permitem que o leitor construa o eixo narrativo de uma história romântica

" "Integral elements of a fiction get dispersed systematically across multiple delivery channels for the purpose of creating a unified and coordinated entertainment experience". 
intercalada por um conjunto de conflitos e situações inusitadas que ocorrem envolvendo os personagens. Como era de se esperar, ao migrar do contexto digital para o meio impresso e assumir uma nova função (não mais um diálogo entre internautas, mas sim segmentos de uma história de ficção), o gênero e-mail sofre alterações. A linguagem, embora mantenha um estilo informal, como ocorre com a maior parte dos e-mails, é mais cuidadosa e fiel às normas de correção linguística, não há erros de digitação e as mensagens produzidas, embora curtas, são mais longas do que as que normalmente são trocadas na internet.

O segundo romance - $A$ visita cruel do tempo - tem como personagem central um executivo da indústria musical que é um ex-integrante de uma banda de punk rock. O enredo induz o leitor a fazer reflexões sobre a música, sobre questões que confrontamos no processo de sobrevivência assim como sobre a transitoriedade de nossos destinos. Nesse romance específico, que tem um total de trezentas e trinta e três páginas, o número significativo de setenta e quatro são imagens. Nessas páginas a narrativa se constrói através da exploração bastante original de diferentes tipos de gráficos que narram, de forma esquemática e visual, as vivências e sentimentos do personagem central.

A leitura desse romance demanda que o leitor tenha em seu repertório de conhecimento prévio a competência para a interpretação de gráficos, inclusive aqueles mais comumente encontrados em relatos de natureza acadêmica. Uma hipótese a ser levantada é a de que esse tipo de habilidade interpretativa também possa serdesenvolvido na interação com infográficos, cada vez mais presentes nos textos da mídia jornalística.
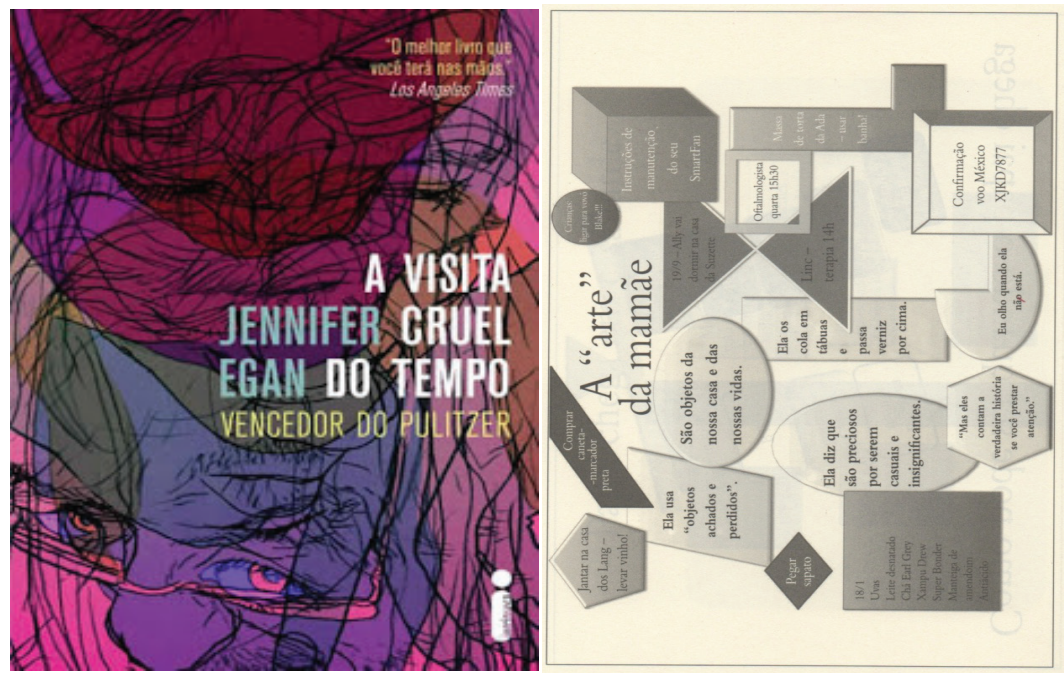

Imagem 1. Capa e exemplo de uma página interna do livro. 


\subsection{Remidiação de textos impressos para o contexto digital.}

Ultimamente, autores literários têm se envolvido em um conjunto de experiências de construções coletivas ou formas novas de publicação de textos. Essas questões não serão discutidas a fundo no presente estudo, mas caminhos possíveis de serem adotados nessa mudança do meio impresso para o digital podem ser bem ilustrados através dos produtos gerados em um projeto publicitário da Penguin Editors.

Nos últimos anos, a Penguin Editors UK tem voltado a sua atenção para a produção de histórias em contexto virtual. Em 2007 a editora lançou o projeto A million Penguins, uma wikinovel (ou romance wiki) que, de acordo com o editor digital Ettinghausen, foi uma experiência na qual ${ }^{12}$ :

Cerca de 1500 indivíduos contribuíram para a escrita e edição de $\boldsymbol{A}$ Million Penguins, contribuindo com mais de 11 .ooo edições fazendo deste, nas palavras do Chefe Executivo da Penguin, 'não o mais lido, mas possivelmente o romance mais escrito da história'. 7.50o pessoas visitaram o site e há mais de 280.000 visualizações da página. ${ }^{13}$

No ano seguinte, teve início o projeto We tell stories ${ }^{14}$. A Penguin desafiou alguns de seus escritores a criar novas formas de contar histórias usando formatos não tradicionais tendo como meio de acesso previsto o digital. Como resultado foram escritas sete histórias baseadas ou inspiradas em clássicos da editora, comentadas a seguir.

A primeira história do projeto foi The 21 Steps, escrita por Charles Cumming e baseada no romance de 1915 The 39 Steps $^{15}$, de John Buchan. Essa nova criação adota como meio o Google Maps, uma ferramenta de localização espacial, para mostrar aos leitores os movimentos do personagem principal que está envolvido em uma conspiração misteriosa.

${ }^{12} \mathrm{D}$ isponível em: http://archive.today/Ehve Acesso em o7ago2014.

${ }_{13}$ "Nearly 1500 individuals have contributed to the writing and editing of A Million Penguins, contributing over 11,ooo edits making this, in the words of Penguin's Chief Executive, 'not the most read, but possibly the most written novel in history'. 75000 people have visited the site and there have been more than 280 ,000 page views".

${ }^{14}$ Os dados do projeto We tell stories estão sendo discutidos mais a fundo em uma tese de doutorado (em andamento) desenvolvida no Departamento de Linguística Aplicada do IEL, intitulada You tell stories, we click on them - análise de novas experiências na produção de histórias multimodais na internet, de Ana Flora Schlindwein, co-autora do presente artigo.

${ }^{15}$ Essa história foi adaptada para o cinema por Alfred Hitchcock (The 39 Steps, 1935, 86 minutos, Reino Unido). 
A leitura dessa obra demanda uma progressão sequencial e o domínio do Google Maps. Diferentemente da mídia impressa, ao interagir com a versão digital a interpretação do leitor é fortemente afetada pelas informações visuais e espaciais presentes, mas, apesar de parecer inovadora, essa versão talvez não seja tão arrojada se considerarmos a prática já sedimentada da leitura de histórias em quadrinhos (doravante HQs). É possível, por exemplo, copiar cada uma das telas na qual a história de Cumming se desenrola, imprimi-las e lê-las sequencialmente, como ocorre com as HQs.

Slice, escrita por Toby Litt (baseada no romance The Haunted Dolls' House, de M. R. James, de 1923) foi publicada durante quatro dias consecutivos através do uso de blogs (dos três personagens principais da trama, a saber: uma adolescente cujo apelido é Slice e seus pais) e de postagens no Twitter.

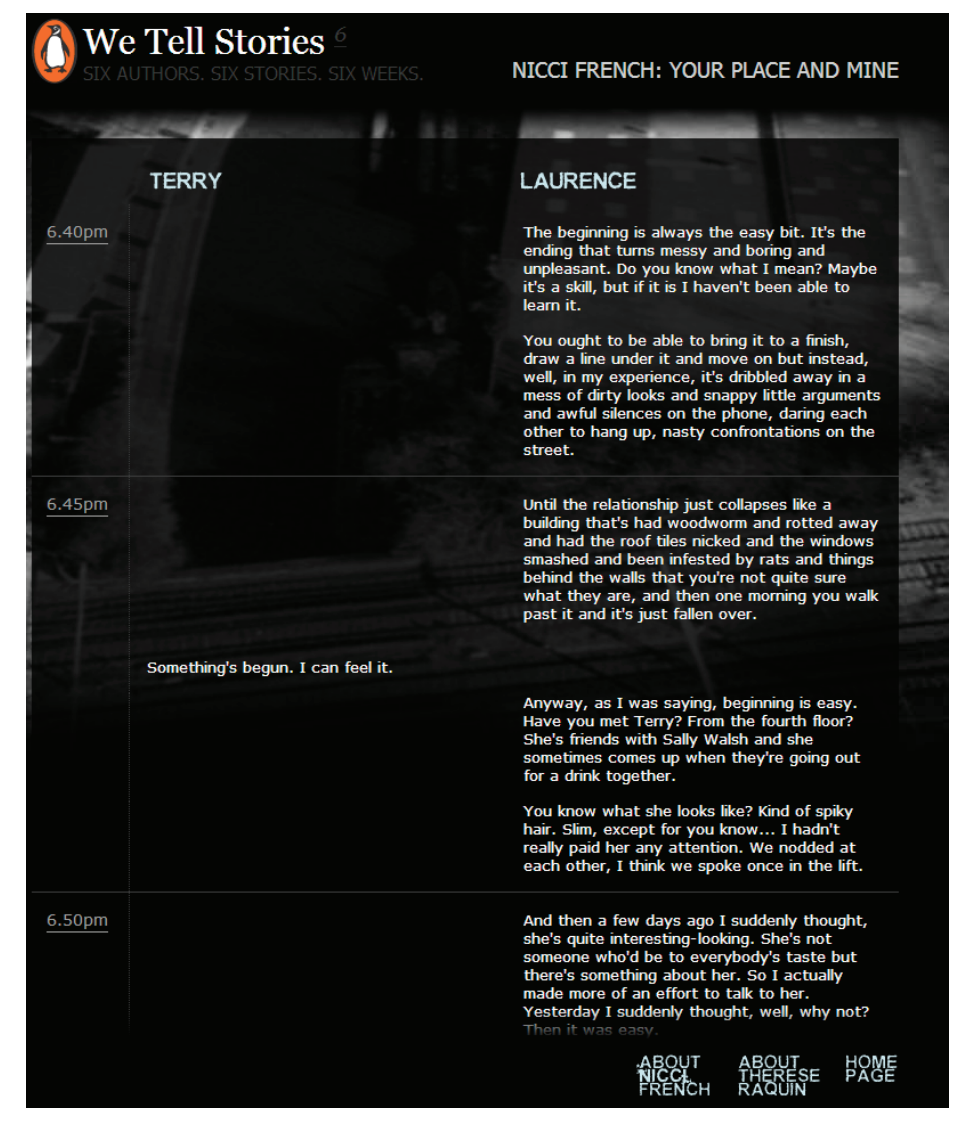




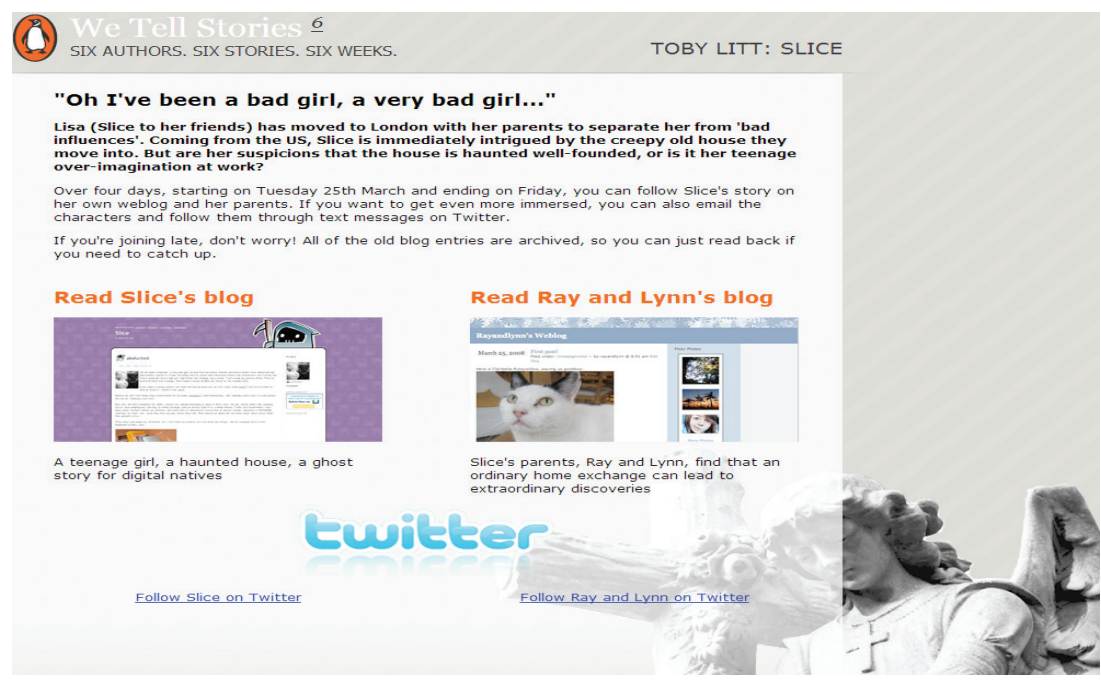

Também foram disponibilizados um email de contato da personagem adolescente e uma página no Flirck com fotos tiradas pelos "pais". Vemos aqui um caso no qual a história se dá em diversos ambientes que oferecem recursos e limites diferenciados.

No caso do blog geralmente há uma interação entre a pessoa que o cria e o mantém e os seus leitores através da ferramenta "comentários", porém, no caso de Slice, a personagem não interage com o seu público através dessa ferramenta, mas sim através de um email. A troca que ocorre no blog é entre os próprios leitores, que comentam não só as postagens de Slice, mas os comentários - que alcançaram o número de 1.004 uns dos outros. Analisando essas interações é possível indagar em que medida o próprio autor não participou dessas trocas "escondido" pelo uso de um pseudônimo, já que alguns dos comentários ofereciam dicas e pistas que complementavam ou aprofundavam parte da história. Essa hipótese, embora plausível, é apenas uma conjectura, já que leitores de comunidades de interesse na rede também assumem esse tipo de papel de esclarecer ou expandir tópicos em discussão.

Your Place and Mine (baseado no romance de Émile Zola Thérèse Raquin) foi publicado simultaneamente à sua escrita, ou seja, durante uma hora por dia, durante cinco dias, os leitores puderam "assistir" à história contada pela dupla conhecida como Nicci French. Para a construção desse texto foi usado um programa de captação de tela que permitia ao leitor acessar a produção dos autores em tempo real. Esse foi um grande desafio para a dupla de escritores, já que a audiência visualizava a escrita em desenvolvimento e não o produto final já revisto pelo editor, como geralmente ocorre com textos publicados. Para o leitor, além do desafio 
de acompanhar esse processo de criação denominado "Performance Storytelling", havia também a possibilidade de participar de uma sala de bate-papo aberta, onde discussões ocorriam em tempo real em paralelo ao processo de produção do texto Your Place and Mine.

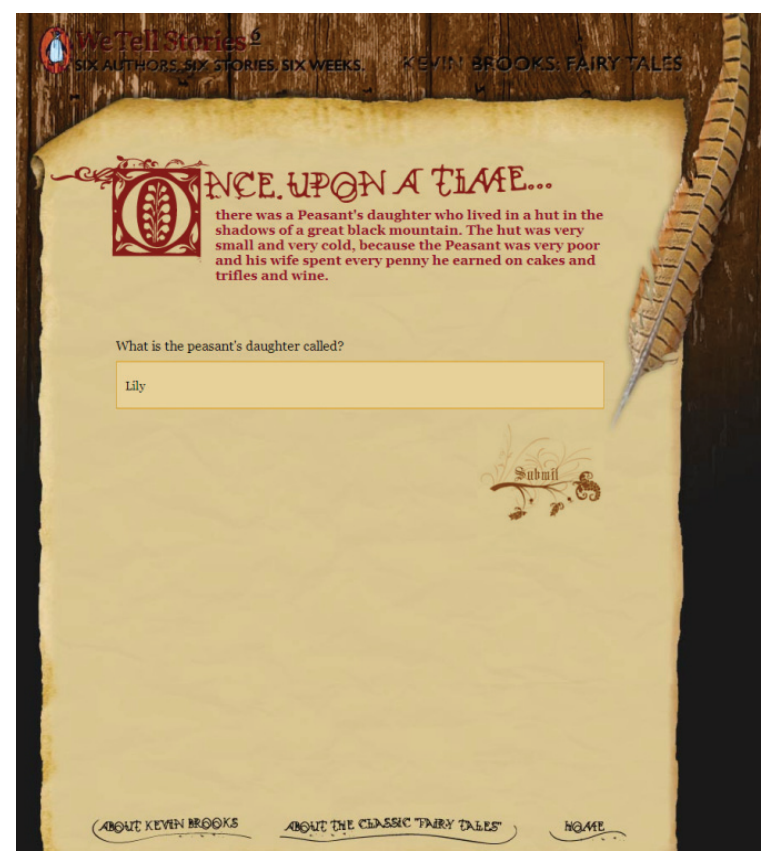

Fairy Tales, de Kevin Brooks (baseado nos contos de fada de Hans Christian Andersen), apresenta uma estrutura que permite ao leitor sua participação na criação de um conto de fadas. Essa iniciativa apresenta um texto no qual o leitor precisa, de tempos em tempos, fazer escolhas de percurso, começando com a dos nomes dos personagens e chegando até a decisões do tipo "com quem você deseja falar" ou "quais são as qualidades mais valiosas para você". Essa forma de construir tramas já vinha sendo explorada em livros do tipo "aventuras solo"16, também chamados de "livro-jogo". Assim sendo, como proposta de construção narrativa Fairy Tales não é inovador, mas é fato que o meio digital facilita muito o uso desse tipo de recurso, já que o leitor não precisa localizar as páginas para dar sequência à trama; precisa apenas clicar na opção desejada.

${ }^{16}$ Nesse tipo e livro o leitor precisa tomar decisões para dar continuidade à história. Por exemplo, o cavaleiro que está tentando salvar a princesa encontra uma porta que pode tanto conduzi-loà donzela como ao poderoso feiticeiro. Se o leitor quiser que o personagem abra a porta ele deverá seguir para a página 38 , se ele quiser que o cavaleiro tente espiar pelo buraco da fechadura, ele deve ir à página 55, e assim por diante. 
Outro aspecto interessante nessa proposta é a abertura que ela dá ao leitor de mudar o texto ao permitir que ele reescreva um final diferente, caso deseje. A história é finalizada com a seguinte mensagem: "Compartilhe a sua história, ou crie outro conto de fadas..." ${ }^{17}$, assim, a versão construída pode ser compartilhada com outros leitores, ampliando de forma potencialmente ilimitada a circulação dessa história.

A história The (Former) General, de Moshin Hamid, é baseada no Tales From the 1001 Nights e usa uma estrutura hipermídia para apresentar as memórias de um general. Esse texto ilustra a maneira como a organização da narrativa dentro de um formato rizomático amplia de forma significativa as possibilidades de leitura. Ao escolher seu percurso o leitor seleciona segmentos particulares de modo a construir textos e leituras singulares.

A princípio, essa descrição pode nos induzir a achar que The (Former) General tem uma estrutura muito similar à de Fairy Tales, porém, de acordo com Dan Hon (designer responsável pelo projeto), embora a ideia tenha sido criar uma história no estilo "aventura solo", tanto o autor quanto a equipe de desenvolvimento queriam ir além. Ao acessar a página, os leitores conseguem ver um diagrama - um mapa de navegação - da história que indica três diferentes caminhos. Ao clicar nas setas, a pessoa decide o seu caminho através da história, mas tem uma localização espacial dos trajetos percorridos devido à "explícita metáfora navegacional espacial"18 adotada, além do minimapa disponível no nível inferior da tela. Com o programa desenvolvido, há o registro de quais células foram acessadas, e ele pode disponibilizar células diferentes baseado nessa informação, criando uma estrutura labiríntica.

Hard Times (inspirado no romance homônimo de Charles Dickens) foi escrita por Matt Mason eaborda questões como leis, política, tecnologia e a forma como ideias são expressas atualmente. Elaborada como uma "história infográfico", pode ser considerada uma narrativa visual ${ }^{19}$, e cabe ao leitor construir a história interpretando os gráficos oferecidos pelo autor. Nesse caso, embora os gráficos sejam disponibilizados em mídia digital, o único recurso de navegação é clicar na página desejada (como mostra a imagem), diferentemente de certos recursos de infográficos que já são disponibilizados em portais de notícias na rede.

${ }_{17}$ "Share your story, or make another fairy tale..."

18 "Explicitly spatial navigational metaphor".

${ }^{19}$ Não vamos debater neste texto se são narrativas visuais apenas as criações estruturadas a partir de uma sucessão de imagens - sejam elas desenhos, fotos, pinturas, gráficos, etc. - que se integram e/ou se vinculam sem que ocorra a presença de linguagem verbal. 
(a)
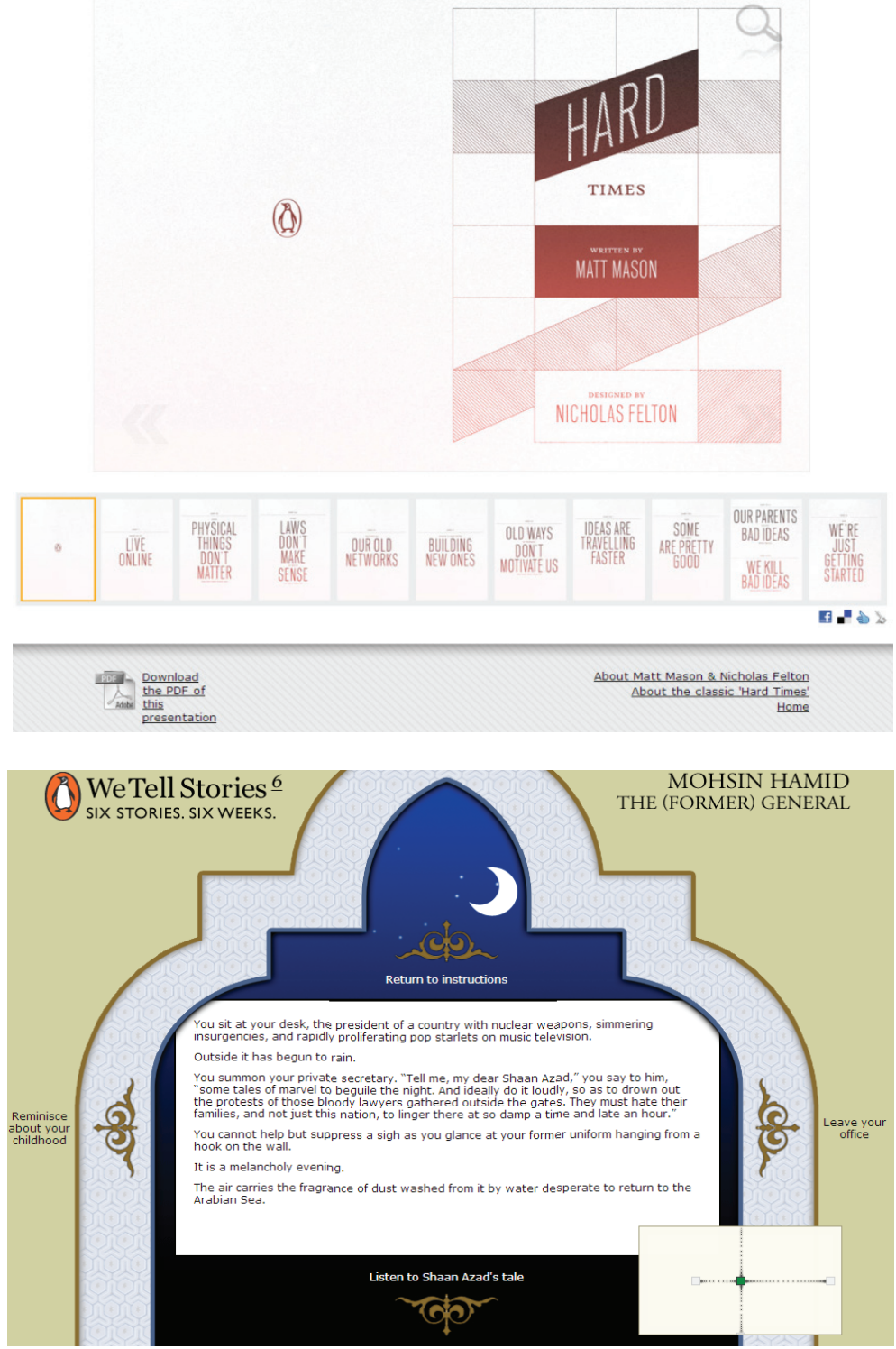

De certa forma, a estrutura de Hard Times se aproxima da composição disponibilizada no formato impresso pela autora Jennifer Egan em A visita cruel do tempo, e já comentada antes, principalmente quando observamos que é possível baixar uma versão em arquivo "pdf" da história escrita por Matt Mason. 
Assim, pelo fato dessas histórias terem sido apresentadas através de blogs, do uso da ferramenta Google Maps, do Twitter, entre outros levaram a Penguin a afirmar que "Essas histórias não poderiam ter sido escritas 200, 20 ou até mesmo 2 anos atrás"2o.

Baseada em Alice's Adventures in Wonderland, de Lewis Carroll, a sétima história, Alice in Storyland, escrita por Naomi Alderman, é construída através de pistas contidas nas outras seis histórias e classificada como uma "alternate reality narrative" ${ }^{21}$. A maneira como foi concebida permitia que os leitores estivessem em contato com a história, na qual poderiam interferir ao ajudar os personagens e ao influenciar o enredo, a partir de participações em sites, e-mails, mensagens de texto e eventos ao vivo. Alice in Storyland é uma excelente ilustração de transmídia storytelling, uma vez que mostra como uma única história foi sendo construída através de mídias diferentes.

Em relação ao último exemplo, a intenção da Penguin com esse projeto foi "[p]arcialmente reunir as seis histórias de uma maneira integrada, assim como trazer o público de ARG [jogos de realidade alterada]", e "tomar toda a vantagem do imediatismo, da conectividade e da interatividade que agora são possíveis"22 (CARLESS, 2008). Com essa estratégia a editora esperava instigartanto o interesse dos leitores com relaçãoàs sete histórias (publicadas na forma tradicional impressa) que serviram de base para a criação das novas versões, como divulgar também sete autores contemporâneos que possuíam outras obras que estavam prestes a ser lançadas. Ou seja, a editora buscava, por meio de um jogo inteligente de marketing, explorar as mídias atuais de forma a provocar a curiosidade sobre obras já existentes e dar visibilidade a lançamentos futuros (também impressos), dando destaque ao nome desses autores através da sua participação em uma experiência de vanguarda. Mas essa experiência só foi possível graças à participação da empresa Six to Start ${ }^{23}$ - que vinha se destacando no campo de Alternative Reality Games para realizar o design das histórias.

${ }_{20}$ "These stories could not have been written 200, 20 or even 2 years ago". Disponível em: http://wetellstories.co.uk/about Acesso em o7ago2014.

${ }^{21}$ Uma alternate reality narrative é uma narrativa interativa cuja história é construída através do uso de múltiplos meios (Walker, 2004), como o mundo real e as mídias interativas. Sua estrutura, portanto, faz dela uma transmídia storytelling, o que permite que a trama possa ser alterada através das intervenções feitas por seus leitores.

${ }_{22}$ "partly to unite the six stories in an integrated way, as well as to bring in an ARG [alternate reality game] audience" (...) "take full advantage of the immediacy, connectivity and interactivity that is now possible" (CARLESS, 2008).

${ }^{23}$ Disponível em: http://www.sixtostart.com/ Acesso em o7ago2014. 
Em uma entrevista concedida à revista Aiga, Dan Hon (co-fundador da empresa e atual CEO) comentou que a Penguin queria investigar novas formas de contar uma história, paralelamente à tentativa de atingir pessoas que não liam livros no formato tradicional impresso, mas que poderiam ser introduzidas ao universo dos clássicos através de material interativo. Nas palavras de Hon: "Nós queríamos experimentar e ver se nós conseguiríamos verdadeiramente abrir novos caminhos online"24 (WILLIS, 2008). Ao fazer um balanço do projeto um ano depois do lançamento de We tell stories, Ettinghausen (editor digital da Penguin) comentou que quase meio milhão de pessoas tinham passado cerca de 9000 horas lendo o material do site. Além disso, a Penguin recebeu muita publicidade positiva, e que "talvez ao longo do caminho tenhamos vendido um ou dois livros a mais ;-)"25. Ettinghousen também ressaltou o quanto eles estavam satisfeitos por terem recebido o prêmio por Experimentation e Best of Show do South by Southwest Interactive Festival Web Awards ${ }^{26}$.

\section{Implicações para a prática de ensino de literatura.}

As obras selecionadas e brevemente comentadas envolveram dois romances impressos e sete propostas de construção de narrativas digitais. Esses exemplos buscaram ressaltar como na prática os conceitos de hibridização de linguagens, de remidiação e de transmídia storytelling são úteis para descrever algumas das muitas mudanças que hoje têm ocorrido nas formas de expressão de um modo mais geral, e nas manifestações artísticas em particular. A passagem de um meio para outro demanda mudanças no nível da linguagem, já que cada um deles oferece um conjunto diferenciado e particular de recursos expressivos e também de limites. O processo de remidiação (BOLTER e GRUSIN, 1999) promove uma interação dialética complexa entre diferentes tipos de linguagens. Convenções semióticas ultrapassam as barreiras impostas pelos meios de comunicação deixando marcas nos processos de criação e inovação de linguagens - o que não é de forma alguma algo novo e inesperado e nem foi desencadeado pela tecnologia digital, apenas reflete as formas como seres humanos constroem sentidos e se comunicam através de diferentes

24 "We wanted to experiment and see if we could genuinely break new ground online"

25 "perhaps along the way we even sold an extra book or two ;-)". Disponível em: http://penguinukbooks.wordpress.com/page/25/ Acesso em o7ago2014.

${ }^{26}$ Disponível em: http://sxsw.com/interactive Acesso em o7ago2014. 
tipos de linguagens. Mesmo nos usos da linguagem oral - nossa forma de comunicação mais básica -, grupos letrados exploram convenções da escrita quando ressaltam que determinados termos estão sendo usados "entre aspas", quando "abrem e fecham parêntesis" e quando enfatizam o término de argumentações com uma expressão como "e ponto final”.

A integração de mídias no meio digital sóveio deixar mais evidente esse processo de hibridização de semioses (SANTAELLA, 2007) e certamente tornou mais dinâmico o processo de mudanças nas diferentes formas de expressão devido ao fato de as ferramentas de autoria disponíveis no meio digital permitirem que pessoas não especializadas possam construir produções multimodais hipermidiáticas e publicá-las para acesso aberto. Feitas essas considerações, é fato que o ensino de uma forma mais geral está ainda bastante defasado em relação às mudanças sociais e de linguagem que estão ocorrendo. O processo de escolarização sempre foi e continua sendo extremamente conservador. Não é de se estranhar, portanto, que o trabalho escolar com a leitura e a produção de textos, literários ou não, tenha ficado à margem dessas mudanças e optado por explorar gêneros escritos impressos. Os exemplos apresentados neste estudo apontam para a necessidade de revermos tal direção.

Em relação aos romances impressos selecionados para a discussão, nota-se a hibridização de gêneros discursivos e formas de expressão que migram do meio digital para o impresso. Embora o uso de gráficos seja bastante presente em determinados gêneros impressos, é fato que a exploração desses recursos na construção de uma parte expressiva da narrativa de um romance é inovadora. A opção por tal forma de tecer a história, em $A$ visita cruel do tempo, talvez possa ser interpretada como uma sensibilização de Jennifer Egan para o processo de visualização da comunicação (KRESS e VAN LEEWEN, 1996 e 2001), esta sim, fortemente influenciada pelos textos veiculados em contexto digital.

Já as diferentes propostas de construção de narrativas adotadas pelos autores que participaram do projeto We tell stories são um alerta aos professores de um modo em geral; um alerta de que a produção e a leitura de textos demandam o domínio de semioses múltiplas. Os modos de acesso a segmentos textuais organizados em forma de rede - hipertextos - exige uma participação bastante ativa do leitor, que precisa determinar seu próprio caminho de leitura e, nesse processo, construir o texto que lê. Diferentes escolhas de percursos definem a composição de realidades textuais distintas. O projeto da Penguin Editors também nos permite identificar uma tendência para formas cada vez mais coletivas e participativas no processo de produção e interpretação de narrativas. Dentro desse direcionamento, o papel de leitor e autor se alternam e se interligam. 
Na Linguística Aplicada, essas questões vêm sendo debatidas na área dos estudos dos novos letramentos e, em relação à escola, o foco do debate é o ensino da produção textual e da leitura com finalidade de construção de conhecimentos e participação social mais ampla. Há toda uma parte extremamente relevante sobre o papel das artes na sociedade que tem sido deixada de lado ou trabalhada de forma superficial. Como destacado na introdução deste texto, o olhar interdisciplinar produz mais questões que respostas. Fica, portanto, registrada uma questão mais ampla, considerando a função social da literatura e das artes: como o professor deve trabalhar a fruição literária contemplando esse conjunto de mudanças semióticas e interações que os diferentes ambientes digitais demandam e instigam?

\section{REFERÊNCIAS BIBLIOGRÁFICAS}

BOLTER, J.; GRUSIN, R. Remediation: understanding new media. Cambridge (MA): MIT Press, 1999.

CARLESS, S. Q\&A: “Perplex City Creators Craft 'We Tell Stories”. In: Gamasutra, 18mar2oo8. Disponível em: http://www.gamesetwatch.com/2008/03/16-week/ Acesso em o7ago2014.

JAMESON, F. Pós-modernismo, a lógica cultural do capitalismo tardio. Tradução de Maria Elisa Cevasco. São Paulo: Ática, 1996.

JENKINS, H. Transmedia Storytelling 101. 22mar2007. Disponível em: $\quad$ h $t$ t p : / / henryjenkins.org/2007/03/transmedia_storytelling_101.html Acesso em o7ago2014.

KRESS, G.; VAN LEEUWEN, T. Reading Images: The Grammar of Visual Design. Oxford: Routledge, 1996.

KRESS. Multimodal Discourse: The Modes and Media of Contemporary Communication. London: Hodder Arnold Publication, 2001.

MANOVICH, L. The Language of New Media. Cambridge (MA): MIT Press, 2000.

MURRAY, J. Hamlet no Holodeck - o futuro da narrativa no ciberespaço. Tradução de Elissa Khoury Daber e Marcelo Fernandes Cuzziol. São Paulo: Itaú Cultural: Unesp, 2003.

SANTAELLA, L. Culturas e artes do pós-humano. São Paulo: Paullus, 2003.

SANTAELLA, L. “As linguagens como antídotos ao midiacentrismo”. Matrizes. São Paulo: n. 1, p. 75-97, 2007.

SNYDER, I. "Antes, agora, adiante: hipertexto, letramento e mudança”. Tradução de Marcelo E. K. Buzato e Ana Elisa Ribeiro. Educação em Revista, vol. 26, no.3, Belo Horizonte, dezembro de 2010. 


$$
652 \text { - Remate de Males } 34.2
$$

WALKER, J. "Distributed Narrative: Telling Stories Across Networks". Apresentado no evento da Association of Internet Researchers (AoIR), em Brighton (Inglaterra), 21set2004. Disponível em: http://jilltxt.net/txt/AoIR-distributednarrative.pdf Acesso em 07 ago2014.

WILLIS, H. "We Design Stories: The Digital Fiction of Six to Start". In: AIGA, 22jul2oo8. Disponível em: $\quad$ http://www.aiga.org/content.cfm/we-design-stories-thedigital-fiction-of-six-to-start Acesso em o7ago2014. 